\title{
Occupational exposure to volatile organic compounds in the Portuguese printing industry
}

\author{
S. Viegas \\ Escola Superior de Tecnologia da Saúde de Lisboa, \\ Instituto Politécnico de Lisboa (ESTeSL/IPL) CIESP, \\ Centro de Investigação e Estudos em Saúde Pública, \\ Escola Nacional de Saúde Pública, \\ Universidade Nova de Lisboa, Portugal
}

\begin{abstract}
In the printing industry, volatile organic compounds main sources are the uses of organic solvents, fountain solutions and cleaning agents.

Nowadays, one circumstance which might confuse the exposure reality is that the majority of solvents which are often used have a faint odour. Therefore, the conditions at offset printing in regard to solvent exposure may seem acceptable to workers. Fortunately, general ventilation and local exhaust systems have also become more common, and new printing machines, often with automatic cleaning, have entered the market.

The health effects of volatile organic solvents are dependent on the chemicals involved but, normally, are associated with affecting the nervous system, the liver and also the kidneys.

The purpose of this study was to document the conditions regarding exposure to volatile organic compounds in an offset printing unit and to permit identify task with higher exposure and with priority for preventive measures application.

Exposure assessment was done before and after installation of general ventilation and local exhaust equipments and during printing and cleaning procedure. It was use portable VOCs measurement equipment with real-time measurements (MultiRAE, RAE Systems model) that allowed identify task with higher exposure.

The need and appropriateness of ventilation introduction is measured by the significant statistically difference $(\mathrm{p}<.001)$ in the concentration results before
\end{abstract}


and after installation, in ppm (Before: Mdn 50.1; St. Deviation 16.9; Min. 8.4; Máx. 85.5 / After: Mdn 11.2; St. Deviation: 7.2; Min. 0.3; Máx. 31).

The results of this study indicate that, actually, the most important source of volatile organic compounds exposure in this printing industry is the cleaning product and, probably, the conditions how this activity is develop promote exposure.

Keywords: volatile organic compounds, printing industry, occupational exposure, ventilation dispositive.

\section{Introduction}

Solvents are complex chemical mixtures containing many different hydrocarbon types, such as alkanes, alcohols, ketones, aldehydes, esters, ethers, and small aromatic molecules that evaporate and become incorporated into environmental air as volatile organic compounds (VOCs) [1].

In the printing industry, the main sources of VOCs are the use of organic solvents, inks, fountain solutions and, also, cleaning agents. Therefore, considerable amounts of vaporized toluene, xylenes, alcohols, and other airborne organic compounds are emitted to the indoor air [2].

Besides printing others processes and operations may cause serious VOC emissions, namely proofing, ink mixing, cleaning, binding, laminating, and chemical storage. Previous studies have reported occupational exposure to various VOCs during all these operations [2-6].

Since the late 1970s the use of organic solvents in the printing industry has been linked to acute intoxication and decreased performance in behavioural tests [3]. Evidence has also indicated a close relation between occupational VOCs exposure and consequential adverse health effects on workers in the printing industry in many countries $[1-4,7,8]$. Health effects include impairment of colour vision, liver dysfunction, hyperglycemia, some neurological symptoms, and cancers [2].

Meanwhile, since the early 1980s the printing industry has made efforts to reduce the exposure to VOCs [5]. Toluene, xylene and chlorinated hydrocarbons have been replaced by paraffins and cycloparaffins with high boiling points, and to some extent with water-based solvents and terpenes. However, despite these improvements, exposure to VOCs is still present in the printing industry [3].

The main purpose of this study was to understand the exposure conditions regarding VOCs in one offset printing unit before and after ventilation equipment installation. Additionally, more than comparing with reference values, the intention was to identify the task with higher exposure and, consequently, with priority for preventive and protective measures application.

\section{Materials and methods}

A printing facility located in south of Portugal was studied during four years. In order to obtain the details of occupational VOCs exposure in the industrial unit, field VOCs measurements were conducted in 27 measurement points during 
printing (near printing machines) and in 1 point during printing machine cleaning. During the four years, two assessments were performed; first assessment was done before ventilation equipment installation and, the second, after installation of general and located ventilation.

In this research, real-time measurements of VOCs concentrations were performed using portable equipment ((MultiRAE, RAE Systems model calibrated by isobutylene). The detection technique used in this equipment is Photo Ionization Detection (PID) (with $10.6 \mathrm{eV}$ lamp). The use of this equipment permitted to identify worst case scenario (peak concentrations) concerning to VOCs exposure.

The PID equipment was zeroed outside the industrial unit in fresh air prior to start measurements. All measurements were done in the breathing zone of workers while they were performing their tasks, during 5 to 15 minutes. It was consider the highest concentration obtained in each measurement point. Only two tasks were studied, namely printing (before and after ventilation installation) and cleaning operations (only after ventilation installation).

Concerning statistical analysis, non-parametric Mann-Whitney U-test was used to evaluate differences between the two conditions, namely before and after ventilation equipment installation. Previous to that, deviation of variables from normal distribution was evaluated by the Kolmogorov-Smirnov test.

Data statistical analysis was performed with SPSS for Windows statistical package, version 17.0 for Windows ${ }^{\circledR}$ of Microsoft International ${ }^{\circledR}$.

\section{Results}

The ventilation device adopted was designed by several hoods placed over the area of cylinders of the three printing machines existed in the printing facility (local ventilation). In addition three exhausted ventilation equipment were installed near the roof of the unit (general ventilation).

The results obtained during the two environmental monitoring actions (before and after installation of ventilation) revealed, in all measurement points, lower values after installing ventilation devices (on average, 9 times less). Before installation, concentration results varied between $20 \mathrm{ppm}$ and $85 \mathrm{ppm}$. After ventilation installation, results varied between $0.3 \mathrm{ppm}$ and $28 \mathrm{ppm}$ (Table 1).

Statistical tests demonstrated that results obtained before ventilation installation $(M d n=50.1 \mathrm{ppm})$ were significantly different from results after installation $(M d n=11.2 \mathrm{ppm}), \mathrm{W}=407, \mathrm{z}=-5.81, p<.001$.

Concerning the task with the higher peak concentration, cleaning operation obtain highest value (146.6 ppm) even after ventilation devices installation. This operation was studied in normal conditions, namely with disconnected ventilation and without protective masks and gloves, considering that chemical absorption can occur by inhalation but, also, by dermal exposure. We have also to consider that frequency of doing this task depends on production exigencies. 
236 Environmental Health and Biomedicine

Table 1: $\quad$ Results of VOCs concentration during printing.

\begin{tabular}{|c|c|c|}
\hline $\begin{array}{l}\text { Measurement } \\
\text { point }\end{array}$ & $\begin{array}{l}\text { Before ventilation installation } \\
\qquad(\mathrm{ppm})\end{array}$ & $\begin{array}{l}\text { After ventilation installation } \\
\qquad(\mathrm{ppm})\end{array}$ \\
\hline 1 & 60 & 31.0 \\
\hline 2 & 85 & 16 \\
\hline 3 & 51.2 & 11.5 \\
\hline 4 & 51.2 & 12.3 \\
\hline 5 & 51.2 & 12.7 \\
\hline 6 & 55 & 12.8 \\
\hline 7 & 42.5 & 11.2 \\
\hline 8 & 39 & 10.8 \\
\hline 9 & 51.8 & 11.6 \\
\hline 10 & 51 & 10.1 \\
\hline 11 & 51.6 & 10.2 \\
\hline 12 & 50 & 11 \\
\hline 13 & 50.6 & 11.6 \\
\hline 14 & 50.6 & 12 \\
\hline 15 & 50.1 & 12 \\
\hline 16 & 48.8 & 10.3 \\
\hline 17 & 49.5 & 11.3 \\
\hline 18 & 49 & 4.2 \\
\hline 19 & 8.4 & 0.9 \\
\hline 20 & 20.1 & 0.3 \\
\hline 21 & 85 & 28 \\
\hline 22 & 51.6 & 11 \\
\hline 23 & 32 & 0.7 \\
\hline 24 & 24.9 & 5.2 \\
\hline 25 & 24.3 & 5.4 \\
\hline 26 & 24.1 & 5.4 \\
\hline 27 & 42 & 23.8 \\
\hline Stand Deviation & 16.5 & 7.1 \\
\hline
\end{tabular}




\section{Discussion}

Study developed not intent to obtain results to compare with reference value since there are no available specific exposure criteria for VOCs due to their different composition, depending basically of the emission source (paints or cleaning products for instance) and task performed.

Nevertheless, measurement of VOCs concentration in two different moments permitted, in this case, to assess protective measures efficacy (ventilation equipment). Obtained results demonstrate the ventilation importance in chemical exposures reduction, also confirmed in other similar studies, namely Ryan et al. [5] and Leung et al. [2].

In addition, in this research, the cleaning process was identified as the task with higher peak concentration, contributing to the increase of short-term workers exposure. Studies developed in the same occupational setting obtained similar results, indicating higher exposures in the cleaning process $[2-4,6,9]$. Moreover, this task is performed without ventilation and, therefore, VOCs can also be present after the cleaning and result in an overall increased VOCs level that can possibly promote the exposure of workers that are not involve in this task [4].

This study illustrates that worker in this industry use aerosol cleaning products under uncontrolled conditions. As a consequence, they receive an inhalation dose of VOCs during each cleaning action. However, in the case of cleaning actions, some factors have to be consider because can influence exposure, namely the distance from breathing zone to the surface (generally the cartridges of the printing machines) that depends of the length of the workers arms and the way of task performing; the vapor pressure of solvents used, which are normally high; and the air change rate near the breathing zone, which is minimal in the absence of ventilation working.

Peak exposures, intense exposures of short duration, are a special concern because the high concentration produces a high dose rate into the body and target tissue, which may alter metabolism, overload protective or repair mechanisms, and amplify tissue responses. As a result, a peak can produce more and different effects than the same administered dose given with less intensity over a longer time period [10-12]. Therefore, knowing the task with higher peak concentration is extremely important to define priorities for the appliance of preventive and protective measures.

Furthermore, development of real-time measurements offers the possibility of defining exposure distributions on time scales relevant to directly relate performance with exposure. This kind of measurement resource is well describe in a study performed by Viegas et al. [13] that also permitted to identify the tasks that involve higher peak exposure to formaldehyde in ten pathology and anatomy laboratories and one formaldehyde-based resins production factory [13].

VOCs characterization was not possible but, normally, one of the most present chemicals in this occupational setting is isopropanol [3]. Isopropanol has a known effect on the central nervous system and is irritating to mucous membrane. Moreover, when used in combination with chlorinated solvents, also 
presented in the printing industry, isopropanol reinforces their effect on the liver [3]. Considering that recommend limit concentration for short-term exposures in Portuguese Norm 1796 (2007) is 400 ppm, none of the obtain results were above this reference value [14]. Meanwhile, and because we are dealing with exposure to a mixture of chemicals, risk assessment have to consider possible synergetic or additive effects in workers health.

\section{Conclusions}

Considering to preventive measures is important to use low-VOC paints in the printing industry but also, and take into account that cleaning operation obtains the highest peak concentration, low-VOC and low-toxicity cleanup products.

Also, in this study, was possible to demonstrate the importance of ventilation devices for reducing exposure to VOCs and, therefore, to protect workers health.

\section{References}

[1] Mendoza-Cantú, A, Castorena-Torres, F, León, M, Cisneros, B, LópezCarrillo, L, Rojas-García, A, Aguilar-Salinas, A, Manno, M, Albores, A, Occupational Toluene Exposure Induces Cytochrome P450 2E1 mRNA Expression in Peripheral Lymphocytes. Environmental Health Perspectives. 114 (2006) 494-499.

[2] Leung, M, Chun-Ho, L, Han, A, Occupational exposure to volatile organic compounds and mitigation by push-pull local exhaust ventilation in printing plants. Journal of Occupational Health. 47 (2005) 540-547.

[3] Svendsen, K, Rognes, K, Exposure to Organic Solvents in the Offset Printing Industry in Norway. Annals of Occupational Hygiene. 44 (2000) 119-124.

[4] Wolkoff, P, Schneidera, T, Kildesoa, J, Degerthb, R, Jaroszewskic, M, Schunkd, H, Risk in cleaning: chemical and physical exposure. The Science of the Total Environment. 215 (1998) 135-156.

[5] Ryan, T, Hart, E, M, Kappler, L, VOC Exposures in a Mixed-Use University Art Building. American Industrial Hygiene Association Journal. 63 (2010) 703-708.

[6] Sutton, P, Wolf, K, Quint, J, Implementing safer alternatives to lithographic cleanup solvents to protect the health of workers and the environment. Journal of Occupational and Environmental Hygiene. 6 (2009) 174-187.

[7] Muttray, A, Wolters, V, Jung, D, Konietzho, K, Effects of high doses of toluene on color vision. Neurotoxicol Teratol. 21 (1999) 41-45.

[8] Kaido, T, Honda, Y, Kitamura, K, Association between liver dysfunction and hyperglycemia in Japanese male workers at printing and papermaking plants. Journal of Occupational Health. 44 (2002) 401-406.

[9] Wadden, R, Scheff, P, Franke, J, Conroy, L, Javor, M, Keil, C, Milz, S, VOC Emission Rates and Emission Factors for a Sheetfed Offset Printing Shop. American Industrial Hygiene Association Journal. 56 (2010) 368-376. 
[10] Smith, T, Studying peak exposure: toxicology and exposure statistics. In: Marklund, S., ed. lit. - Exposure assessment in epidemiology and practice. Stockholm: National Institute for Working Life. (2001) 207-209.

[11] Vyskocil, A, Thuot, R, Turcot, A, Peak exposures to styrene in Quebec fibreglass reinforced plastic industry. In: MARKLUND, S., ed. lit. Exposure assessment in epidemiology and practice. Stockholm: National Institute for Working Life. (2001) 316-318.

[12] Preller, L, Burstyn, I, De Pater, N, Characteristics of peaks of inhalation exposure to organic solvents. The Annals of Occupational Hygiene. 48 (2004) 643-652.

[13] Viegas, S, Ladeira, C, Nunes, C, Malta-Vacas, J, Gomes, M, Brito, M, Mendonça, P, Prista, J, Genotoxic effects in occupational exposure to formaldehyde: A study in anatomy and pathology laboratories and formaldehyde-resin production. Journal of Occupational Medicine and Toxicology. (2010) 5-25. http://www.occup-med.com/content/5/1/25.

[14] Instituto Português da Qualidade - NP 1796: 2007: segurança e saúde do trabalho: valores limite de exposição profissional a agentes químicos existentes no ar dos locais de trabalho. Caparica: IPQ, 2007. 